\title{
Future wind, wave and storm surge climate in the northern North Atlantic
}

\author{
Jens Debernard*, Øyvind Sætra, Lars Petter Røed
}

Research and Development Division, Norwegian Meteorological Institute, PO Box 43, Blindern, 0313 Oslo, Norway

\begin{abstract}
In this paper we consider a possible change in future wind, wave, and storm surge climate for the regional seas northeast of the Atlantic: the northern North Atlantic. Conclusions are based on a statistical analysis of the results derived with state-of-the-art wave and storm surge models run for two 20 yr time-slice periods, one for the period 1980 to 2000 (control climate) and one for the period 2030 to 2050 (future climate). Forcing was derived by extracting atmospheric wind and sea level pressure from a state-of-the-art regional atmospheric climate model for the same two $20 \mathrm{yr}$ periods. These regional atmospheric simulations constitute dynamical downscales of the Max Planck Institute's global scenario which includes greenhouse gases, sulphate aerosols (direct and indirect effects) and tropospheric ozone. Generally the changes we found are small. However, there are some important exceptions, such as a significant increase in all variables in the Barents Sea and a significant reduction in wind and waves north and west of Iceland. Also, there is a significant increase in wind speed in the northern North Sea and westwards in the Atlantic Ocean, and a comparable reduction southwest of the British Isles in the autumn. The same change is suggested for wave height, but this is not statistically significant There is a significant increase in the seasonal 99 percentile of the sea level in autumn in the southwest part of the North Sea. These results are consistent with earlier studies predicting a rougher maritime climate in the northern North Sea in autumn.
\end{abstract}

KEY WORDS: Dynamical downscaling $\cdot$ Sea state $\cdot$ Climate change $\cdot$ Wave climate $\cdot$ Surge climate Resale or republication not permitted without written consent of the publisher

\section{INTRODUCTION}

Based on global warming scenarios (e.g. IPCC 2001) concern is raised regarding possible future roughening of wave climate and a rise in sea level in the northern North Atlantic, i.e. the Norwegian, Greenland and Iceland Seas together with the adjacent North Sea and Barents Sea. The concern is raised based on global simulation that projects a future higher frequency and intensity of storms. The present study aims at giving insight into this by studying a projection of future regional wave and storm surge climate based on one of the IPCC scenarios.

\subsection{Background}

Global coupled atmosphere-ocean general circulation models (AOGCMs) have for some time predicted global warming due to increased discharge of green- house gases. The credibility of these models increases because observations of the global mean temperature during the 20th century seem to fit reasonably with their predictions. According to the Intergovernmental Panel on Climate Change (IPCC 2001) most of the observed warming over the last $50 \mathrm{yr}$ is likely to be due to the increase in greenhouse gas concentrations, which in turn is probably a consequence of increased consumption of fossil fuel since the beginning of the industrial age. The most sophisticated AOGCMs reproduce variations in the observed global mean temperature during the last $100 \mathrm{yr}$. However, although different global models predict a relatively consistent rise in global mean temperature, regional changes are highly variable and at the present stage the regional effects of global climate change must be regarded as far from conclusive.

One important reason for these large regional differences is that the global models, and in particular the 
ocean model component, are integrated forward with a grid resolution too coarse to simulate the regional flow patterns in any adequate way. A remedy is to dynamically downscale results from an AOGCM by nesting a high-resolution regional atmospheric climate model (RACM), or coupled atmosphere-ocean model, into a subdomain of the global model simulation, e.g. Jones et al. $(1995,1997)$ and Bjørge et al. (2000). The results from the global model are then used as lateral boundary conditions for a regional climate simulation. Provided that the global simulation gives a realistic description of the large-scale circulation patterns, the nested high-resolution model integration may be used to project the climate variability on the finer regional scale.

An earlier study of regional change in sea state focusing on the North Atlantic, the WASA project (Waves and Storms in the North Atlantic; WASA 1998), analysed available data of storms and waves. Their main conclusion was that the storm and wave climate in most of the Northeast Atlantic and in the North Sea has undergone significant variations on time scales of several decades and has roughened in recent decades. They also conclude that the present intensity of the storm and wave climate seems to be comparable with that of the beginning of the 20th century. In addition, IPCC (2001) states that based on limited data the observed variations in the intensity and frequency of tropical and extra-tropical cyclones and severe local storms show no clear trends in the last half of the 20th century, although multi-decadal fluctuations are sometimes apparent. However, in a recent study Pfizenmayer \& von Storch (2001) found an increase in the frequency of eastwardly propagating waves in the central North Sea that significantly deviates from what is expected from their analysis of natural variability. By comparing with results from downscaled AOGCM scenarios they suggest this change to be a local manifestation of anthropogenic global climate change. Regarding storm surges, Langenberg et al. 1999 analysed changes in mean and extreme sea level around the North Sea using statistical and dynamical methods. For the extreme events they conclude that the natural variability is too large to detect any significant changes.

In the present paper, a scenario for future wave and storm surge climate is studied by forcing stand-alone, state-of-the-art wave and storm surge models with $10 \mathrm{~m}$ wind and sea level pressure obtained from an atmospheric dynamical downscale experiment of a global climate change scenario. This gives a dynamical but computationally expensive prediction of probable change in sea-state climate. The method of forcing stand-alone regional models with downscaled or reanalysed atmospheric forcing has been used in studies of both past and future wave and storm-surge climates (WASA 1998, Langenberg et al. 1999, Lowe et al. 2001).

\section{METHODOLOGY AND MODELS}

\subsection{The climate change scenario and the atmospheric downscale experiment}

The climate change scenario used in the downscaling experiment was obtained from the Max Planck Institute's ECHAM4 atmosphere model coupled to the OPYC3 ocean model. The scenario, denoted GSDIO, includes changes in greenhouse gases, sulphate aerosols (direct and indirect effects) and tropospheric ozone. The concentrations of greenhouse gases follow the observed concentrations of $\mathrm{CO}_{2}$ up to 1990 followed by a $1 \%$ increase of $\mathrm{CO}_{2}$ per yr (IPCC IS92a). The GSDIO scenario differs from the ECHAM 4/OPYC3 scenario (only greenhouse gases, but same emission scenario) employed in some other studies of changes in sea-state climate (Kaas et al. 2001, Pfizenmayer \& von Storch 2001). Compared with GHG, the GSDIO scenario gives a more realistic global mean temperature up to year 2000 and a smaller global temperature increase up to year 2050. The zonally averaged temperature increase north of $72^{\circ} \mathrm{N}$ is $2^{\circ} \mathrm{C}$ smaller in the GSDIO than in the GHG simulation in 2050 (Roeckner et al. 1999).

The regional atmospheric climate model (RACM) used for the dynamical downscale is a modified version of the forecast model HIRLAM (High Resolution Limited Area Model, Källen 1996) with ECHAM4 physics. For details cf. Christensen et al. (1996), Bjørge et al. (2000). The model was first verified successfully against present climate by dynamically downscaling the European Centre for Medium Range Weather Forecasts (ECMWF) reanalysis data (ERA15) (Bjørge \& Haugen 1998) before dynamical downscaling of the GSDIO scenario. The downscale experiment and the atmospheric results are described by Bjørge et al. (2000). However, to better understand the effect of wind changes on the predicted changes in waves and storm surge a slightly more detailed analysis of the changes in wind speed is performed here.

The downscaling consists of 2 time-slice periods of $20 \mathrm{yr}$ each, one from 1980 to 2000 and a second from 2030 to 2050 . These periods are henceforth referred to as the control climate and the future climate, respectively. The difference between the 2 time-slices is then taken to represent 1 possible regionalised climate change scenario for the next $50 \mathrm{yr}$.

The RACM was run on a rotated spherical grid with the grid south pole at $25^{\circ} \mathrm{S}, 0^{\circ} \mathrm{E}$. The resolution was 0.5 $\times 0.5$ degrees. Thus, the global GSDIO scenario is downscaled from about $300 \mathrm{~km}$ to about $55 \mathrm{~km}$. The downscale area is shown in Fig. 1. At lateral boundaries, 12-hourly values from the global model are lin- 
early interpolated in time. Sea ice concentration and sea surface temperature are specified by the monthly mean values from the global simulation.

The necessary forcings to drive the wave and storm surge model were extracted from the regional model every every $6 \mathrm{~h}$. The wave model utilized the $10 \mathrm{~m}$ wind, whereas the surge model uses both $10 \mathrm{~m}$ wind and sea level pressure.

\subsection{The wave model}

To project wave climate the upgraded version of the WAM-model at the Norwegian Meteorological Institute is used. This version is used daily to provide wave forecasts. WAM was originally developed by the WAMDI group (WAMDI group 1987), and is upgraded in accord with the changes reported by ECMWF (Bidlot et al. 1997).

The wave model was implemented and integrated on exactly the same computational domain and grid as employed in the atmospheric downscale (Fig. 1). For practical purposes the two $20 \mathrm{yr}$ simulation periods are divided into 4 periods of $5 \mathrm{yr}$ each. At the beginning of each integration period the wave model is cold-started from an empirically calculated spectrum determined from the local wind (Pierson \& Moskowitz 1964). Since the wave energy propagates through the whole model domain within a period of approximately $24 \mathrm{~h}$, the spin-up time of the model is ca. 1 to $2 \mathrm{~d}$. This entails that for 1 to $2 \mathrm{~d}$ during each $5 \mathrm{yr}$ integration period, the

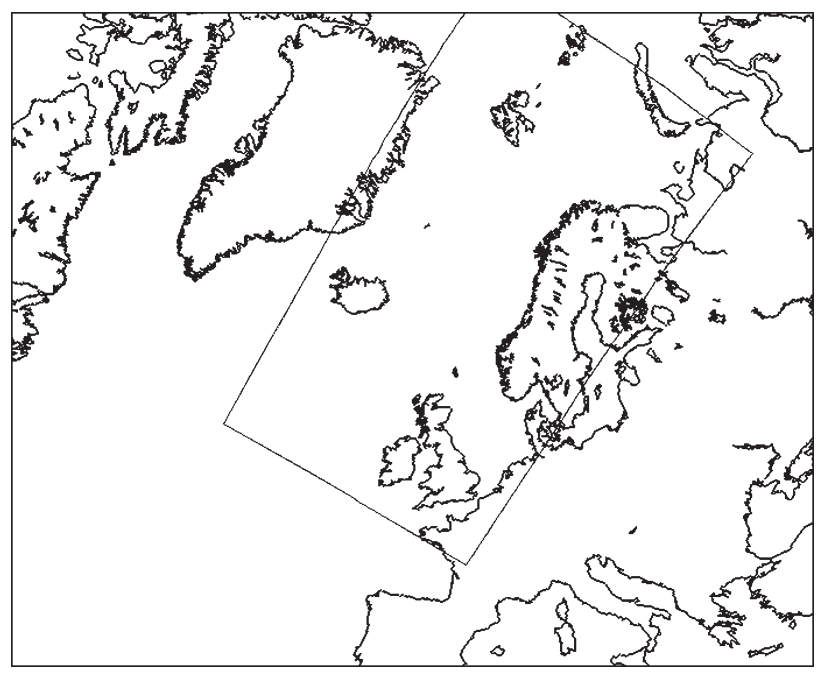

Fig. 1. Simulation area for storm surge model (small frame), inserted into simulation area of the regional atmosphere model and wave model. Northern corner of storm surge model area extends outside the area of atmospheric data. Here, data are extrapolated from nearest atmospheric data points, which have negligible influence on the results wave energy will be underestimated in the simulations. However, it is felt that this period is too short to have any significant effect on the overall wave statistics. At open boundaries, a zero energy condition is used.

In the wave simulations, the sea ice cover is held fixed at a climatologically observed extent during all the simulations. This sea ice cover is seen as undefined points in the wave results and will generally differ from the sea ice concentration used in the atmospheric downscale experiment. Alternatively the sea ice extent of the global simulation could have been used, as for instance was done in the RACM. However, this would give areas with undefined points in 1 simulation which would become defined points in the other simulation and vice versa. We therefore opted to use the climatologically defined ice border.

\subsection{The storm surge model}

The storm surge climate is derived using the Norwegian Meteorological Institute's version of the Princeton Ocean Model (POM; Blumberg \& Mellor 1987) as documented in Engedahl (1995a) and Engedahl et al. (2001). Except for some minor modifications which allow for tidal forcing combined with climate years (360 $\left.\mathrm{d} \mathrm{yr}^{-1}, 30 \mathrm{~d} \mathrm{mo}^{-1}\right)$, this model conforms to the model used by the Norwegian Meteorological Institute to produce daily ocean forecasts of tides, ocean currents and sea level. The model configuration is the same as that employed by Hackett (2001) in his study of the surge climate changes along the Norwegian coast in the STOWASUS-2100 project (Kaas et al. 2001). The simulations are done on a polar stereographic map projection with a horizontal grid resolution of $30 \mathrm{~km}$. This grid and domain differs from that employed by the RACM as displayed in Fig. 1.

The two 20 yr time-slice periods were simulated separately. Each period was initialised using sea level height and depth-integrated currents from a climatological archive (Engedahl et al. 1997), which provides monthly mean values of all the ocean variables. These climatological variables were also utilised at the open boundaries throughout the integration, applying the Flow Relaxation Scheme (FRS) as an open boundary condition (Martinsen \& Engedahl 1987, Engedahl 1995b). Due to the rapid propagation of barotropic waves, effects of the initial condition are only seen for 1 to $2 \mathrm{~d}$ and have a negligible influence on the statistics for the whole $20 \mathrm{yr}$ time-slice period. For each timeslice, the model was run with atmospheric and tidal forcing. However, in both simulations, the tidal forcing, which included 8 diurnal and semidiurnal constituents, was started from the same astronomical date. To filter 
out the tides, the results from a reference simulation with only the tidal forcing were subtracted from the time-slice results. In this way, the tides are removed, while the effect on the surge by possible tide-surge interactions is kept. Sea ice was not included in the surge simulations.

With the present boundary conditions, the model does not include the effects of global sea level rise due to thermal expansion of seawater or enhanced melting of glaciers. Thus the present study concentrates only on the direct consequences of changes in sea level due to the impact of atmospheric wind and pressure forcing. A global sea level rise may change the storm surges in shallow areas to increase the phase propagation, so it is not obvious that a global sea level rise could simply be added linearly to the present surge results. However, at least in the North Sea region, the non-linear interaction between a mean sea level rise and the meteorological forced storm surges seems to be small (Lowe et al. 2001).

\subsection{Statistical analysis}

The data were analysed with 2 different statistical methods, a linear trend analysis and a Wilcoxon ranksum test of changes in distributions. The statistical confidence levels of both tests, applied on the present results, are mostly very similar. Only the results from the rank-sum test are presented in the 'Results' section.

For each year we define annual and seasonal values for the mean and 99 percentile of wind speed and significant wave height, and standard deviation and 99 percentile of sea level. These values are based on all the data in the time-series for the period considered, i.e. 6 hourly values for wind and waves and 1 hourly values for sea level. The values are extracted in every grid point in the dataset. Then for each variable we have 40 values, 20 from each time-slice period. For the trend analysis these values are ordered cronologically in a $70 \mathrm{yr}$ time series, with a $30 \mathrm{yr}$ gap from 2000 to 2029. Linear regression analysis gives the best linear fit to these data as a function of time and Student's $t$ test is utilized on data from the analysis to test if the trend is significantly different from zero (Bhattacharyya \& Johnson 1977). Another approach is to consider the values from each time-series as 2 different populations and test if there is a statistically significant difference between the populations. Because these populations are generally not normally distributed, the Wilcoxon rank-sum test is applied (Bhattacharyya \& Johnson 1977). In the 'Results' section the differences between the mean of the 20 values from each timeslice period, normalised by the mean of the values from the control period, and also the statistical confidence level are shown. Values of the confidence level below $10 \%$ mean that the chance of obtaining the present result if the time-slice samples come from the same populations is below $10 \%$. In this case the difference is considered statistically significant.

The mean wind speed, mean significant wave height and standard deviation of sea level are taken as robust measures of the overal wind, wave and surge climate. The mean sea level is not chosen, because this is always very close to zero. The variation in sea level around the mean sea level, as given by the standard deviation, is a more robust measure of the surges. The 99 percentile is considered to be a relatively robust measure of the extreme events. When the relative differences in the 99 percentile of sea level is shown, the difference between the mean 99 percentiles from the time-slices is normalised by the difference between the mean 99 percentile and the mean sea level from the control period. This gives a positive definite denominator that measures the deviation from normal conditions.

To investigate the extreme events at selected sites more closely the 500 highest events of significant wave height and sea level from both time-slices were also extracted (see Fig. 4). In each series, the events are sorted in increasing order. To prevent one storm from biasing the extremes these events are selected such that there is a time span of at least $48 \mathrm{~h}$ between any 2 events. In this way, it is assumed that each event represents an individual storm. A plot of the events from the scenario (future) against the events from the control is then indicative of a change in the wave or surge climate if there is a significant deviation from a 1 to 1 line.

\section{RESULTS}

As revealed by Figs. $2 \& 3$, the distribution of local annual mean wind speed (Fig. 2) is closely connected to that of annual mean significant wave height (Fig. 3) during the control time-slice. Therefore it is expected that changes in wind speed may give a direct change in significant wave height. The connection between wind speed and variations in sea level (Fig. 4) is not as straightforward. This is to be expected since storm surges are not only influenced by wind speed, but also by wind direction and the movement of the storms (Gjevik \& Røed 1976, Martinsen et al. 1979). The degree to which a specific region is affected by a surge is determined to a large extent by the movement of the storm centre that generates the winds. Even small changes in wind direction are crucial to whether a specific site experiences a high surge or not. Except for a 


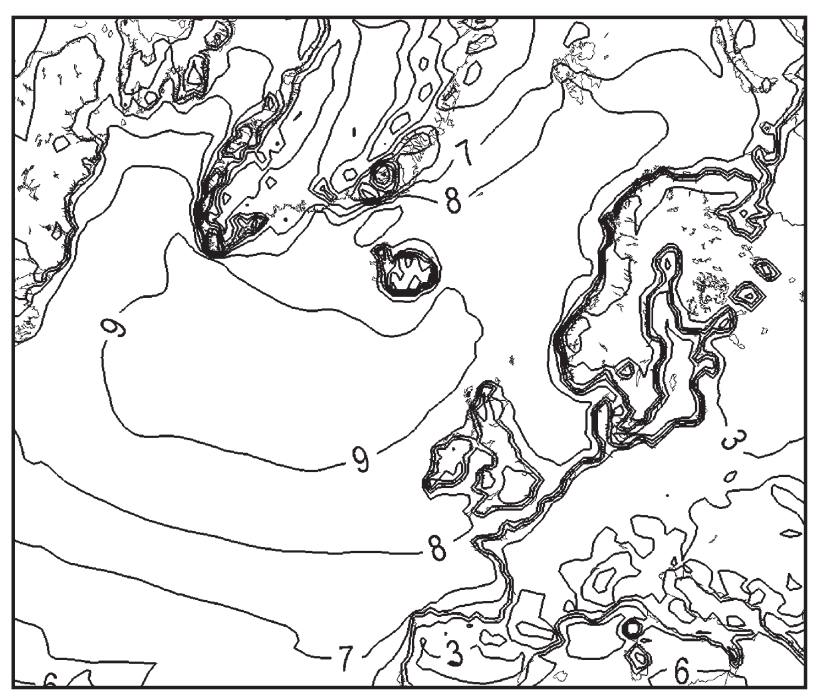

Fig. 2. Annual mean $10 \mathrm{~m}$ wind speed averaged over the control simulation. Equidistant spacing is $1 \mathrm{~m} \mathrm{~s}^{-1}$

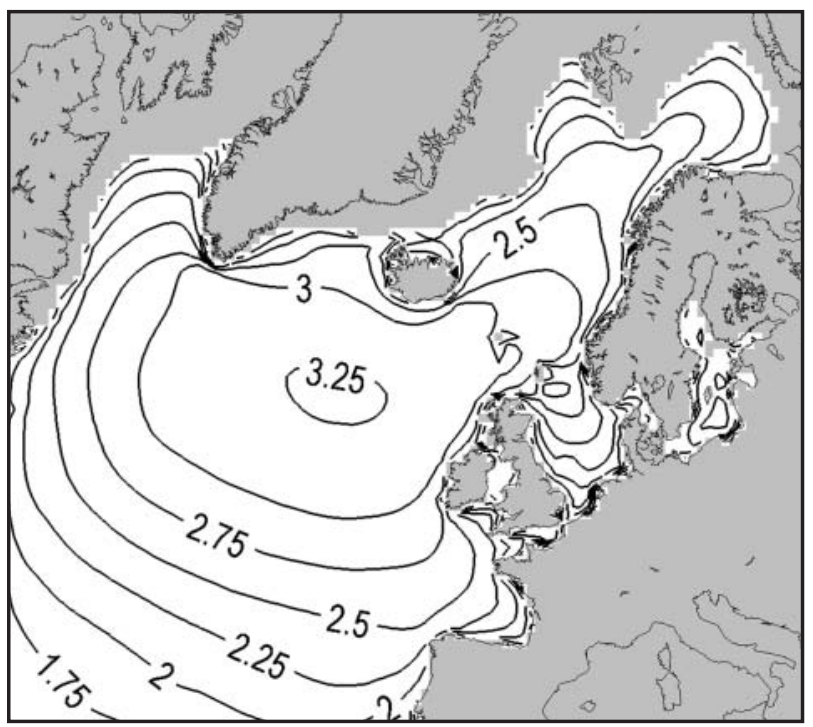

Fig. 3. Annual mean significant wave height averaged over the control period. Equidistant spacing is $0.25 \mathrm{~m}$. Climatologic sea ice cover is used in all wave simulations and land mask is dark grey

few offshore installations in the North Sea, storm surge is mainly important along the coastline, has an inherently local character and is highly influenced by smallscale coastline geometry and bottom topography. A storm surge usually propagates along the coast as a Kelvin wave. Therefore, a single surge event affects large areas, but has very different local impacts depending on the local topography, both over and under the sea level. As indicated by Fig. 4, some of the largest variations in sea level and also the largest surge events are found in the southeastern part of the North Sea.
Fig. 5 shows mean significant wave height from a 9 yr hindcast study based on analysed, 12-hourly winds. Comparing Fig. 3 with Fig. 5, the present wave height seems to be underestimated southwest of the IcelandScotland section. This is mainly because the simulation area for the wave model is too small to capture all of the wave energy propagating northward by long swells in the North Atlantic. A larger simulation area would be preferable, but the present study is bounded by the area with atmospheric forcing obtained from the downscale experiment.

Figs. 6 to 12 show relative changes (\%) of some variables, together with the confidence level from the Wilcoxon test. Red contours denote increases, blue

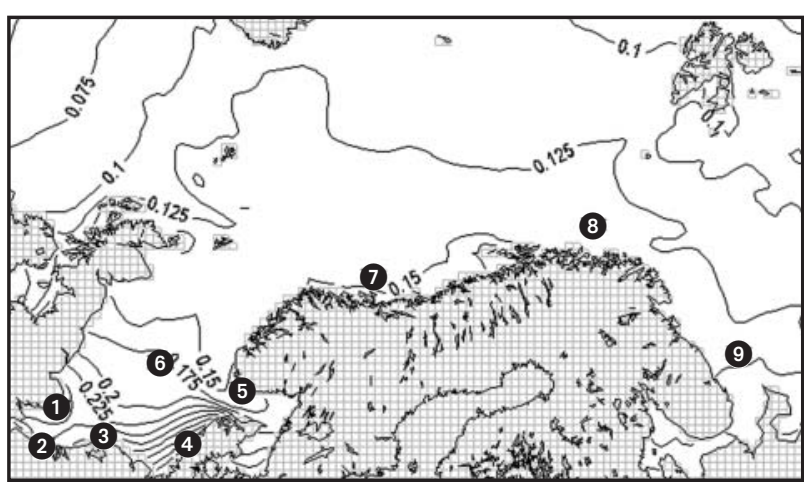

Fig. 4. Standard deviation of sea level based on annual data averaged over the control period. Equidistant space is 0.025 $m$. In addition the stations shown in Figs. $13 \& 14$ are marked: (1) Lowestoft, (2) Oostende, (3) Texel Noordzee, (4) Esbjerg, (5) Tregde, (6) Ekofisk, (7) Haltenbanken, (8) Tromsøflaket and (9) Barents Sea East

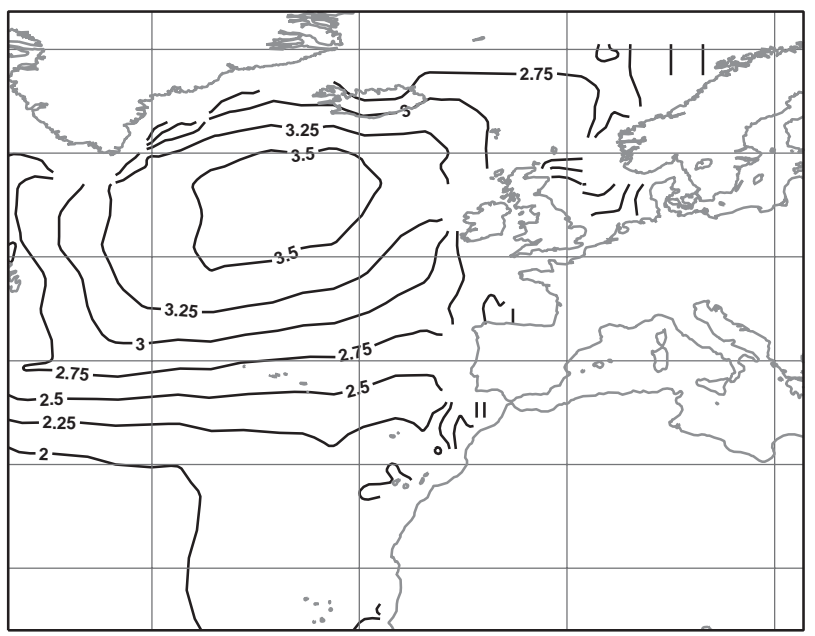

Fig. 5. Results from a 9 yr hindcast of annual mean significant wave height obtained from ECMWF based on 12-hourly analysed winds. Compare with Fig. 3 


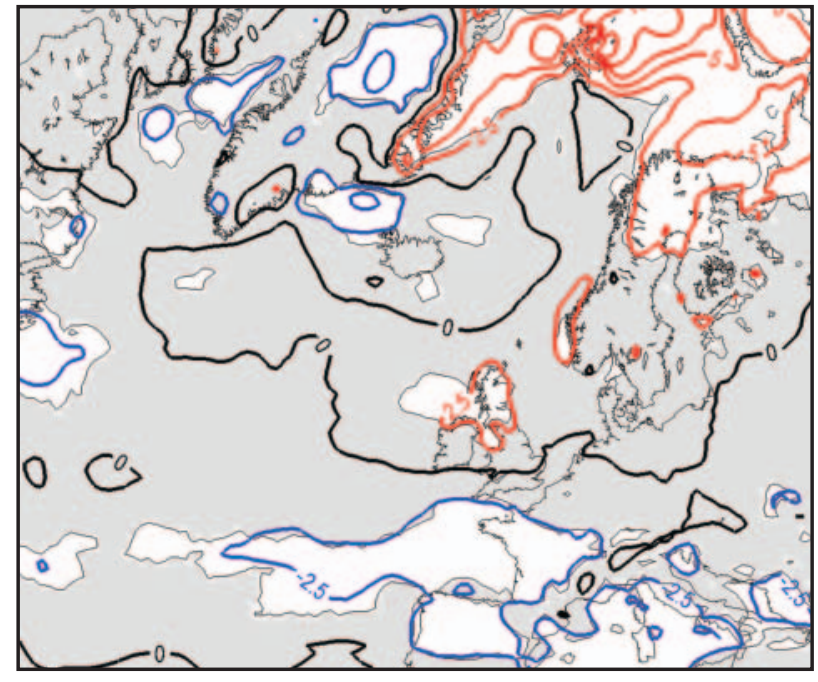

Fig. 6. Relative changes between future and control periods in annual mean wind speed (\%). Red isolines: increases; blue isolines: decreases. White background colour denotes statistical significant changes from the Wilcoxon rank-sum test at $10 \%$ level. Light grey denotes insignificant changes

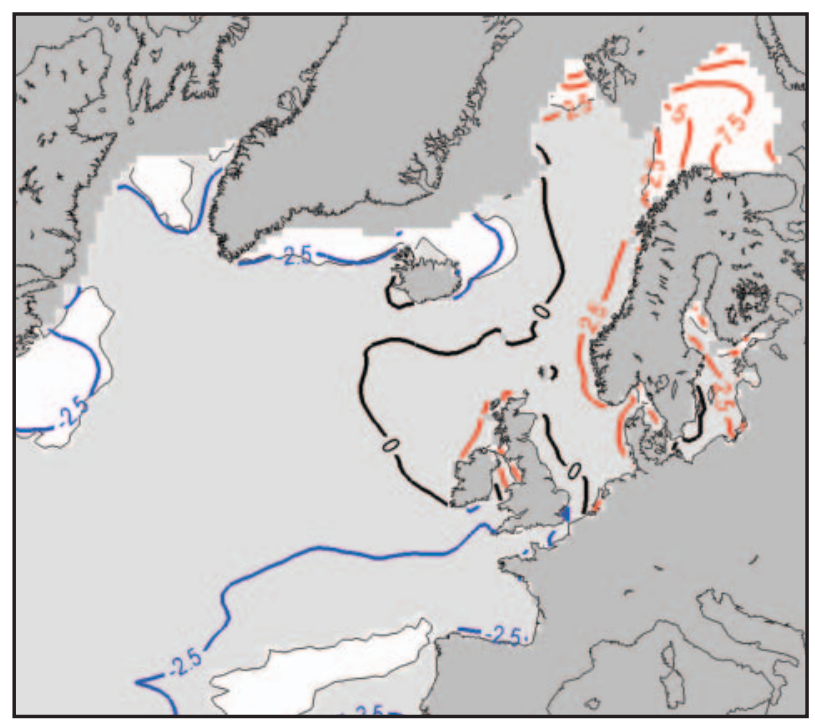

Fig. 7. Relative change in annual mean significant wave height

denotes decreases. White background denotes statistically significant changes at the $10 \%$ level, while lightgray background denotes insignificant changes.

As revealed by Fig. 6, there are rather small changes in the annual mean wind speed, statistically significant at few locations. There is a tendency for statistically significant increases in mean wind speed over Ireland, Scotland and along the western coast of Norway. The same holds true in the Barents Sea and along the marginal ice zone in the Greenland Sea. There is a

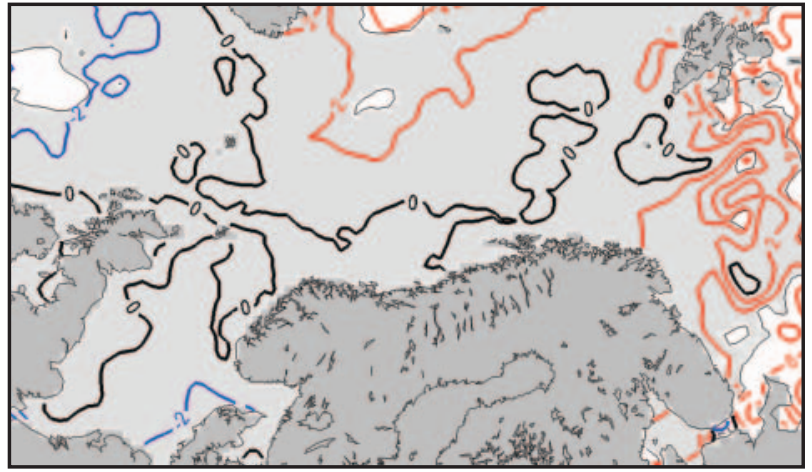

Fig. 8. Relative change in standard deviation of sea level based on annual data

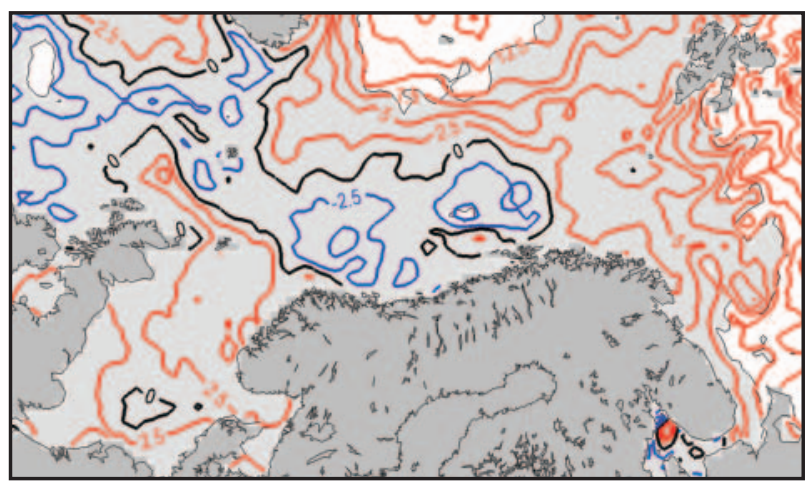

Fig. 9. Relative change in annual 99 percentile of sea level

decrease in both the annual mean wind speed and its 99 percentile (not shown) in a region south of the British Isles in the Atlantic. There is also a decrease in a limited area north and west of Iceland.

Changes in annual mean significant wave height (Fig. 7) show much the same pattern. However, given the high correlation of high wind speed and high mean wave heights shown in Figs. 2 and 3, it is somewhat surprising that the confidence levels of the changes in the waves are much less significant than in the wind. Only the increase in the Barents Sea and the decrease north and west of Iceland are significant.

The changes are also minor for sea level, indicated by Figs. 8 \& 9 showing the change in the standard deviation and the 99 percentile of sea level based on annual data. In the 99 percentile, significant changes are not found in the North Sea or along the Norwegian coast (Fig. 9). Also in the standard deviation, the changes are small.

Of the 4 seasons, the most pronounced changes are found in autumn (September, October, and November). This is exemplified in Figs. 10 \& 11, showing changes in seasonal mean wind speed and wave height. In both variables, there is an increase from the 
south of Greenland eastwards over the northern part of the British Isles towards the coast of the western part of Norway. South of this region, there is a reduction in both wind and waves. While these increases/ decreases are statistically significant in seasonal mean winds, they are again, mostly not significant in the seasonal mean wave height confirming the lack of significance of the changes in wave height for the annual data.

The increased wind over the northern part of the North Sea during the autumn months does have a significant influence on storm surges in the North Sea area as exemplified in Fig. 12 showing the change in the seasonal 99 percentile of sea level for the autumn months. There is a significant increase in several areas, and mostly in the southwest part of the North Sea. In spite of the significant changes in autumn, there is no significant roughening in annual extreme statistics of sea level due to storm surges in the area around the North Sea. This is mainly due to the fact that the most severe events are found in winter when the changes are minor. This finding is reflected in the plot of the 500 largest surge events at selected sites around the North Sea (Fig. 13). At Oostende in the southwest part of the North Sea (see Fig. 4), the increase in autumn storms forms a minor deviation from the dashed line for the medium-height events around $1.5 \mathrm{~m}$. However, there are no clear changes in the higher events, which are winter storms. There is a tendency of reduced surge heights at Esbjerg in the scenario. This is in accordance with the changes in the standard deviation (Fig. 8), but is not reflected in the 99 percentile (Fig. 9). The change in standard deviation at Esbjerg is not significant from the Wilcoxon test shown in Fig. 10. However, the trend analysis of the standard deviation in sea level from the annual data (not shown) gives a significant $(p<0.05)$ reduction at the west coast of Denmark.

\section{DISCUSSION}

The changes in mean wind and waves tend to increase over the northern British Isles and eastwards to the west coast of Norway, whereas there is a reduction south of the British Isles. These changes are seen in the annual results (Figs. 6 \& 7), but mostly in the autumn months (Figs. $10 \& 11$ ). The changes may indicate a northward displacement of the main storm tracks in future climate. Analysis from the same atmospheric downscale of a storm track parameter in autumn (Bjørge et al. 2000), shows a tendency towards increased storm activity and a slight northeasterly shift in the storm tracks. In winter months, there is also a slight increase in the storm track parameter (J.E.

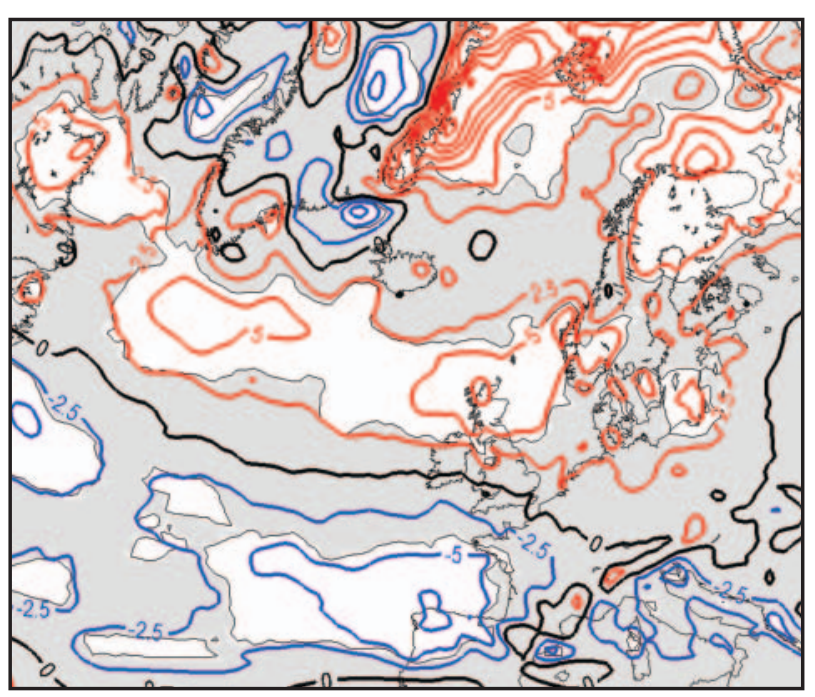

Fig. 10. Relative change in mean wind speed for the autumn season (September, October and November)

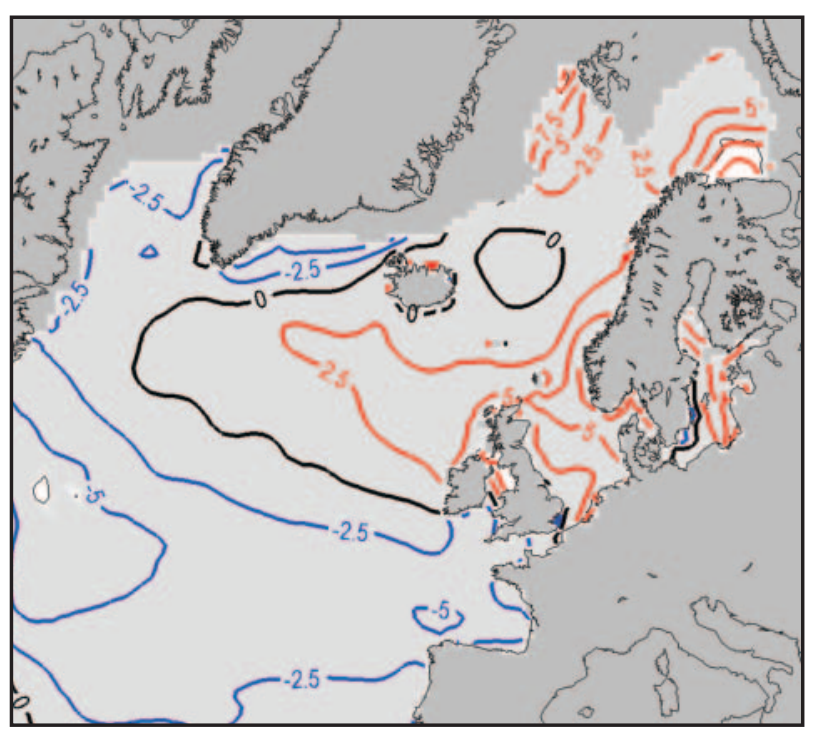

Fig. 11. Relative change in mean significant wave height in the autumn season

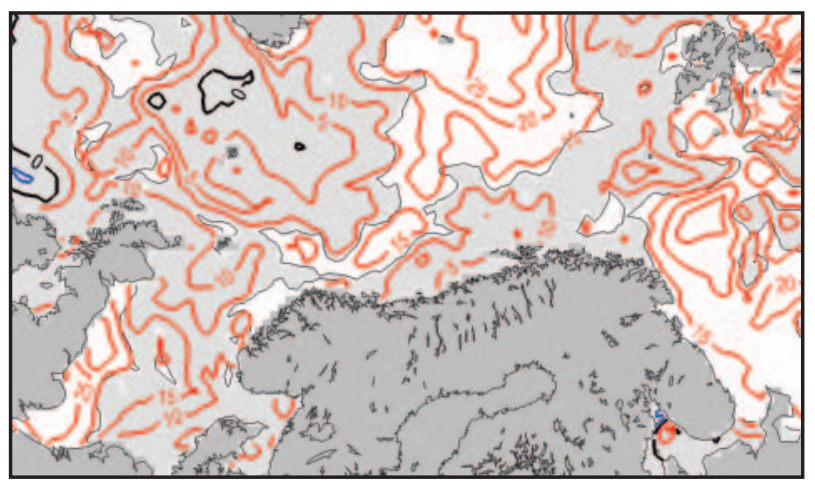

Fig. 12. Relative change in 99 percentile of sea level in the autumn season 

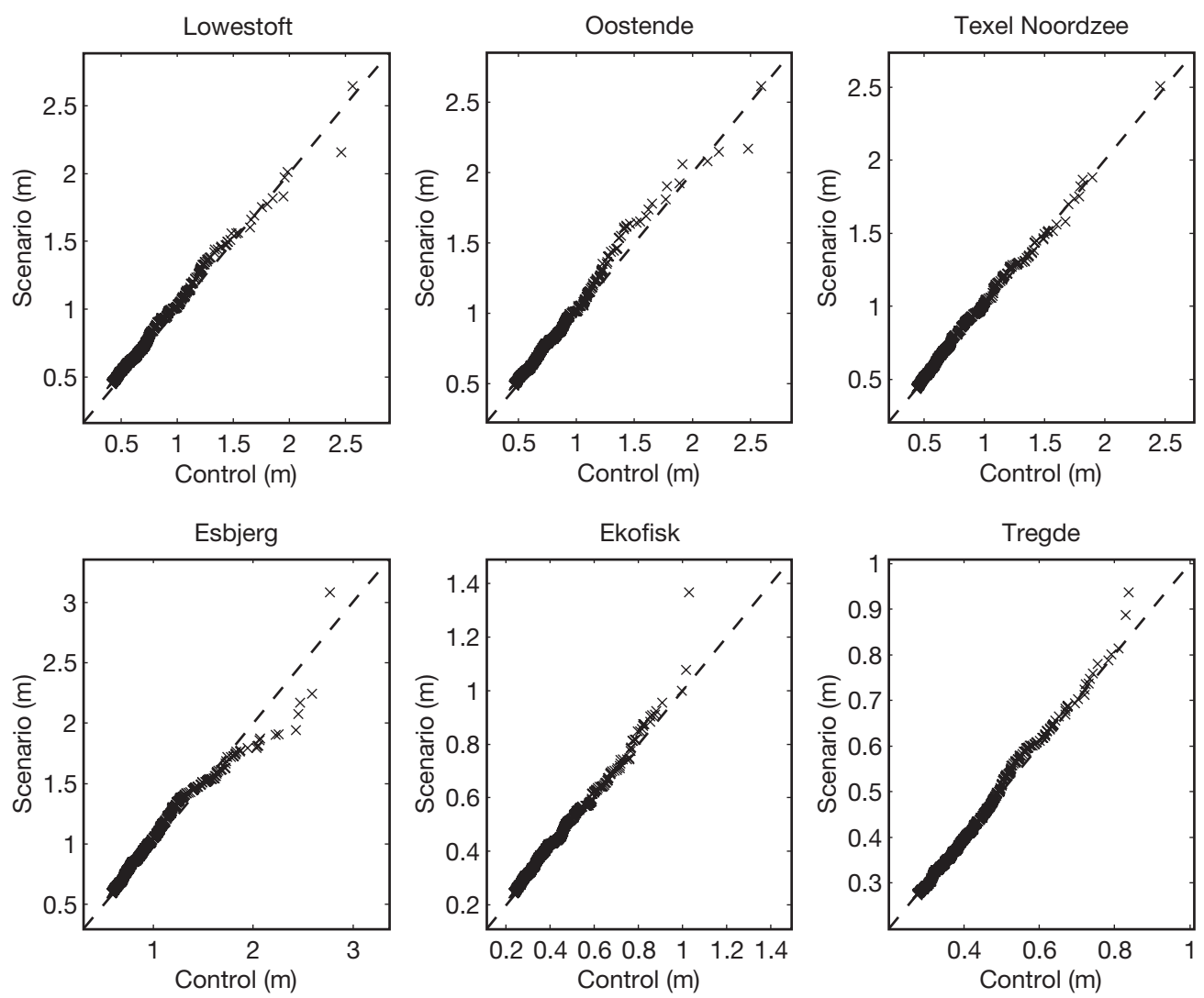

Fig. 13. The 500 highest surge events from control and future climate scenarios. Events in each series are sorted in increasing order and the 2 sorted series are plotted against each other. Geographical locations of the stations are shown in Fig. 4. Deviations from the straight line denote changes in storm surge climate
Haugen, D. Bjørge \& T. E. Nordeng unpubl. manscript). The winter increase may be explained with a slightly enhanced NAO index in the period representing future climate. However, the present analysis shows no significant influence of this increase in the storm track parameter on the winter wind speed and sea state.

The projected changes in wind speed seem to be more statistically robust and significant than the changes in wave height. This may be a little surprising given the strong correlation of high mean wind speed and high mean wave heights shown in Figs. 2 \& 3 and could be due to the fact that not only the wind speed, but also changes in the direction of the wind are important for the growth of waves. No attempts to analyse the variations in wind direction have been made here. However, it seems possible that more rapid changes in wind direction may reduce the effects on wave height. In this way changes in the propagation speed of the atmospheric low pressure systems are also important for the predicted wave heights.

In a similar study with dynamical downscaling by the Max Planck Institute's GHG scenario (Kaas et al. 2001) the wind and wave climate in the northern North Sea and in the Norwegian Sea is found to worsen. They report a predicted change in mean significant wave height in autumn in the range of 5 to $10 \%$ during a $70 \mathrm{yr}$ period. Extrapolating the present trends for the northern North Sea to a $70 \mathrm{yr}$ change gives a similar change of 7.5 to $10 \%$ in the autumn mean wave height. However, this change is not statistically significant based on the present analysis. The present change in the North Sea is similar in magnitude to the results from the GHG scenario even if the GSDIO scenario utilised here has a smaller global and regional warming (consult Section 2.1 on the climate change scenario for differences between GSDIO and GHG). Both the present study and the Kaas et al. (2001) results clearly show that the most significant changes from the present to a future climate may occur in autumn.

Rather small or no changes are found in the annual storm surge climate in the North Sea in the present results. Significant changes are found in the southern and western part of the North Sea in the autumn season, but the changes do not affect the annual extreme statistics. In the annual results, there is a tendency for reduced variability (standard deviation, Fig. 8) west of Denmark, while the 99 percentiles are nearly unaffected (Fig. 9). This tendency contrasts with the results from the Kaas et al. (2001) finding of a significant increase in extreme surge heights along the west coast of Denmark in a warmer climate. However, they also 

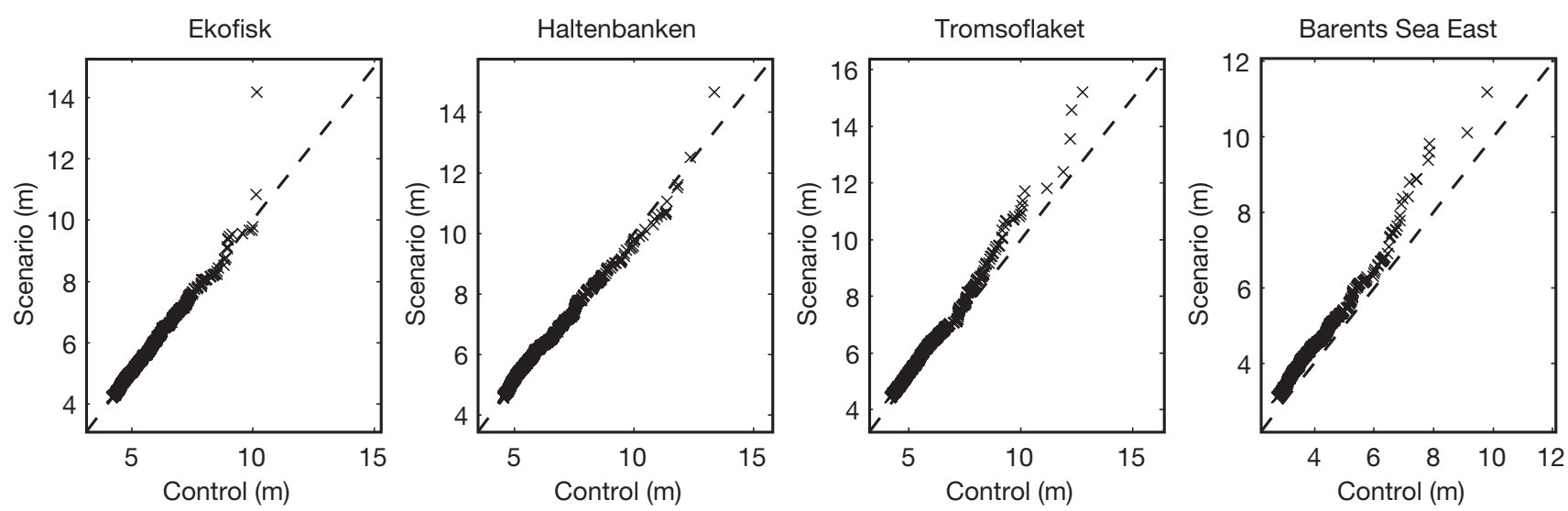

Fig. 14. The 500 highest wave events in control and future climate scenarios from selected offshore stations (see Fig. 4)

point out the large regional variability of the changes in surges within the North Sea area and could not conclude whether the increase is due to global warming or inter-decadal variability. In the southwest part of the North Sea, they found no significant changes. In a study of storm surge climate changes around the United Kingdom, Lowe et al. (2001) used dynamically downscaled atmospheric variables from the Hadley Centre climate model (HadCM2) to force a dynamical surge model. The emission scenario is the same as used in the GSDIO and GHG simulations from the Max Planck Institute (IS92a). They predicted a reduction in extreme surges in the Thames estuary and southern North Sea, but an increase along the east coast of the British Isles, along the Dutch coast, in the German Bight and along the west coast of Denmark.

The regional distribution of the changes found in the present study, compared with the above mentioned results from other studies, confirms that the surge climate is of a local character, and calls attention to the fact that it is very difficult to give any reliable conclusions about future changes without having time-slice experiments long enough to cover the whole natural variability of storm tracks in the new climate. This underscores the need for several comparable analyses based on various different downscale experiments of different global scenarios. Nevertheless, it requires that the model simulations are able to capture the natural variability of the climate system. In this respect, empirical downscale methods may be more effective in downscaling very long or numerous climate change scenarios (e.g. Pfizenmayer \& von Storch 2001). However, these methods are not able to capture possible changes in the physics of the extreme event storms.

The largest changes in the present analysis are the roughening of the maritime climate in the Barents Sea and along the northern coast of Norway. The increase is found in all variables, but perhaps mostly in wind and waves, as exemplified in Fig. 14 showing the plots of the 500 highest wave events. At the northernmost stations, Tromsøflaket and Barents Sea East, there is a clear tendency for increased waves. The roughening in this region occurs in autumn, winter and spring. These are the seasons which already have the roughest climate, entailing a worsening of annual extremes and of the mean statistics. It should be emphasised, however, that this roughening for the Barents Sea and for the marginal ice zones in the Greenland Sea is highly uncertain because both areas are strongly dependent on the sea ice cover used in the atmospheric downscaling scenario. The present downscaling was done with the sea ice cover from the Max Planck Institute's global GSDIO scenario. Other global climate model scenarios may give very different results for the Arctic region, and dynamical downscaling of a different scenario is likely to give different changes in this region. However, there is a consensus among global climate projections that the largest changes are expected in highlatitude areas with a reduction in sea ice extent and snow cover. The present results reflect this change, but also illustrate the difficulties of quantifying the change in a specific region. For instance, the present changes in wind and waves (Figs. 6 \& 7) give a roughening of the climate in the Barents Sea, but less wind and waves northwest of Iceland. We expect that regional coupled atmosphere-ice-ocean models with high horizontal resolution are required to give a proper description of the physical interactions and feedbacks in these regions. The changes in waves reported here for this region are entirely due to changes in wind speed and direction. Reduced ice cover will also increase the wind fetch for the waves, and then further increase the wave heights. This effect is not accounted for in the present study where the ice cover in the wave model was fixed at a climatologically observed extent. 
As indicated by Figs. $13 \& 14$, the highest surge and wave event in the scenario seems to be extraordinarily severe at the Ekofisk and Esbjerg locations. It is the same storm, developed in a cold-air outbreak from the Arctic that affects both sites. The storm starts to develop in mid February at the east coast of Greenland, west of Iceland, and moves eastward out over open water just north of Iceland where it deepens strongly. It then first continues eastward and next turns more southeasterly towards, and over, the southern part of Norway. The result is a relatively long period of northerly to northwesterly winds of 'storm' and 'violent storm' strength in the North Sea (Debernard \& Saetra 2002). Such storm behaviour is not necessarily an effect of warmer climate. By comparing this future storm with those observed within the present day climate, it might in fact be regarded as a nearly worstcase scenario within the present day climate. Some of the most devastating storm situations reported in the North Sea area have followed similar paths (Lamb 1991). However, warmer sea surface temperature, as in the future global scenario used as a boundary condition in the downscaling experiment, may enhance the explosive character of this cyclone as it moves out over the ocean. Much longer simulation periods, combined with detailed storm studies are required to make a final conclusion about whether the strongest storms will get stronger in this region in a warmer climate. However, there are also shortcomings in the model systems that make assessments of extreme events difficult. Most atmosphere models and also the WAM wave model tend to underestimate these peak events.

\section{CONCLUSIONS AND FINAL REMARKS}

State-of-the-art wave and storm surge models were run for two 20 yr time-slice periods (1980 to 2000 and 2030 to 2050) using atmospheric forcing taken from a regional atmospheric climate model, dynamically downscaling 1 particular IPCC scenario, namely the Max Planck Institute's GSDIO scenario. Analysis of changes from the control to the scenario period based on Wilcoxon's rank-sum test and a linear regression reveals mostly small and insignificant changes in wind speed, wave height and storm surges.

However, there are some remarkable exceptions. A significant increase in all variables in the Barents Sea and a significant reduction in wind and waves north and west of Iceland is found. The increase in significant wave height in the Barents Sea is about 7.5 to $12.5 \%$ during a $50 \mathrm{yr}$ period in both annual means and annual 99 percentiles. In this region the changes occur mostly in the autumn and winter season. These changes near the marginal ice zone are closely con- nected to the response of the regional atmospheric climate model to the reduction in the sea ice extent in the future warmer climate predicted by the GSDIO global scenario run.

Furthermore, there is a significant increase in seasonal mean wind speed in the northern North Sea and westwards in the Atlantic Ocean and a reduction southwest of the British Isles in autumn. The same is true for significant wave height, but in contrast to the wind it is not statistically significant. There is also a significant increase in the 99 percentile of sea level due to storm surges in autumn in the southwest of the North Sea.

The annual extreme statistics in the North Sea area are not affected by the increase in autumn storms, because the most severe events are found in the winter season when very small and insignificant changes are found in this area.

Acknowledgements. This research was supported by the Reseach Council of Norway through the national climate project RegClim (Project No. 120656/720). Support for computations has been provided by NOTUR (Norwegian High Performance Computing Consortium) and the ECMWF (European Centre for Medium Range Weather Forecasts) computer facilities.

\section{LITERATURE CITED}

Bidlot J, Hansen B, Janssen P (1997) Modifications to the ECMWF WAM Code. Tech Mem 32, European Centre For Medium-Range Weather Forecasts, Reading

Bjørge D, Haugen, JE (1998) PT1: Simulation of present-day climate in HIRLAM using 'perfect' boundary conditions. RecClim Tech Rep 1, Norwegian Institute for Air Research, Kjeller

Bjørge D, Haugen JE, Nordeng TE (2000) Future climate in Norway; Dynamical downscaling experiments within the RegClim project. Res Rep 103, Norwegian Meteorological Institute, Oslo

Bhattacharyya GK, Johnson, RA (1977) Statistical concepts and methods. John Wiley \& Sons, New York

Blumberg AF, Mellor GL (1987) A description of a threedimensional coastal ocean circulation model. In: Heaps NS (ed) Three-dimensional coastal ocean models. Coast Estuar Ser 4, American Geophysical Union, Washington, DC

Christensen JH, Christensen OB, Lopez P, van Meijgaard E, Botzet M (1996) The HIRHAM4 Regional Atmospheric Climate Model. Sci Rep 96-4, Danish Meteorological Institute, Copenhagen

Debernard J, Saetra $\varnothing ~(2002)$ Future wave and storm surge climate in Norwegian waters. Res Rep 130, Norwegian Meteorological Institute, Oslo

Engedahl H (1995a) Implementation of the Princeton Ocean Model (POM/ECOM3D) at the Norwegian Meteorological Institute (DNMI). Res Rep 5, Norwegian Meteorological Institute, Oslo

Engedahl H (1995b) Use of the flow relaxation scheme in a three-dimensional baroclinic ocean model with realistic topography. Tellus 47A:365-382 
Engedahl H, Eriksrød G, Ulstad C, Ådlandsvik B (1997) Climatological oceanographic archives covering the Nordic Seas and the Arctic Ocean with adjacent waters. Res Rep 59, Norwegian Meteorological Institute, Oslo

Engedahl H, Lunde A, Melsom A, Shi XB (2001) New schemes for vertical mixing in MI-POM and MICOM. Res Rep 118, Norwegian Meteorological Institute, Oslo

Gjevik B, Røed LP (1976) Storm surges along the western coast of Norway. Tellus 23:166-182

Hackett B (2001) Surge climate scenarios in the northern North Sea and along the Norwegian coast. Res Rep 123, Norwegian Meteorological Institute, Oslo

IPCC (2001) Climate change 2001: the scientific basis. Technical summary. Intergovernmental Panel on Climate Change. Cambridge University Press, Cambridge

Jones RG, Muphy JM, Noguer M (1995) Simulation of climate-change over Europe using a nested regional-climate model. 1. Assesment of control climate, including sensitivity to location of lateral boundries. Q J R Meteorol Soc 121B:1413-1449

Jones RG, Murphy JM, Noguer M, Keen AB (1997) Simulation of climate change over Europe using a nested regionalclimate model. 2. Comparison of driving and regional model responses to a doubling of carbon dioxide. Q J R Meteorol Soc 123B:265-292

Kaas E, Andersen U, Flather RA, Williams JA and 18 others (2001) Synthesis of the STOWASUS-2100 project: regional storm, wave and surge scenarios for the 2100 century. Danish Climate Centre, Report 01-3. Danish Meteorological Institute, Copenhagen. Available at: www.dmi.dk/ $\mathrm{f}+\mathrm{u} /$ publikation/dkc-publ/dkcfors.html

Källen E (ed) (1996) HIRLAM documentation manual. System 2.5. Swedish Meteorological and Hydrological Institute, Norrkøping

Editorial responsibility: Hans von Storch, Geesthacht, Germany
Lamb H (1991) Historic storms of the North Sea, British Isles and Northwest Europe. Cambridge University Press, Cambridge

Langenberg H, Pfizenmayer A, von Storch H, Sündermann J (1999) Storm-related sea level variations along the North Sea coast: natural variability and anthropogenic change. Cont Shelf Res 19:821-842

Lowe JA, Gregory JM, Flather RA (2001) Changes in the occurence of storm surges around the United Kingdom under a future climate scenario using a dynamic storm surge model driven by the Hadley Centre climate model. Clim Dyn 18:179-188

Martinsen EA, Gjevik B, Røed LP (1979) A numerical model for long barotropic waves and storm surges along the western coast of Norway. J Phys Oceanogr 9: 1126-1138

Martinsen EA, Engedahl H (1987) Implementation and testing of a lateral scheme as an open boundary condition for a barotropic model. Coastal Engineering 11:603-637

Pfizenmayer A, von Storch H (2001) Antropogenic climate change shown by local wave conditions in the North Sea. Clim Res 19:15-23

Pierson WJ Jr, Moskowitz, L (1964) A proposed spectral form for fully developed wind seas based on the similarity theory of S.A. Kitaigorodskii. J Geophys Res 69:5181

Roeckner E, Bengtsson L, Feichter J, Lelieveld J, Rodhe H (1999) Transient climate change simulations with a coupled atmosphere-ocean GCM including the tropospheric sulfur cycle. J Clim 12:3004-3032

WAMDI group (1988) The WAM model-a third generation ocean wave prediction model. J Phys Oceanogr 18: $1775-1810$

WASA (1998) Changing waves and storms in the northeast Atlantic? Bull Am Meteorol Soc 79:741-760

Submitted: December 26, 2001; Accepted: July 17, 2002

Proofs received from author(s): October 22, 2002 